\title{
Canadian Neurological Sciences Federation 2018 Congress June 24 - 27 Halifax Convention Centre, Halifax, Nova Scotia
}

Sunday, June $24^{\text {th }}, 2018$

8:30 am to $11: 00$ am - Courses

- $\quad$ Stroke - Latest Developments in Ischaemic Stroke

- Neurological Determination of Death

- $\quad$ Neurology Residents' Course - Neurogenetics and Neurometabolics for the Child and Adult Neurologist

- $\quad$ Neurosurgery Residents' Course - Intracranial Hypotension and Disorders of CSF

$11: 15$ am to $12: 15 \mathrm{pm}$ - Poster Moderated Sessions

12:30 pm to 2:00 pm - Lunch 'n Learn sessions

- $\quad$ Thinking Ahead: New Treatment Options for Migraine Prevention

- Innovative Approaches to Surgical Resection Utilizing Modern Ultrasonic Tissue Ablation; A Case Series Discussion 2:00 pm to 4:30 pm - Courses

- $\quad$ Stroke - Latest Developments in Intercranial Hemorrhage

- $\quad$ Epilepsy

- $\quad$ Neurology Residents' Course - Neurogenetics and Neurometabolics for the Child and Adult Neurologist

- $\quad$ Neurosurgery Residents' Course - Neurosurgery Hot Seat

5:30 pm to 7:30 pm - Clinical Case Studies (CCS)

- Neuromuscular

- $\quad$ Epilepsy Video Session

- $\quad$ Neurosurgery-Fireside Chat

- Movement Disorders

- $\quad$ Case Based Session-Neuroradiology

7:30 pm - Residents' and Faculty Social

Monday, June $25^{\text {th }}, 2018$

8:00 am to $12: 00 \mathrm{pm}$ - Grand Plenary

- $\quad$ CSNR - Terbrugge Lecture: Jean Raymond, Problems with the Introduction of Innovations in Neurovascular Care

- $\quad$ CNS - Richardson Lecture: Mark Freedman, Does Replacing the Immune System Fix Multiple Sclerosis?

- $\quad$ CSCN - Gloor Lecture: Robert Fisher, Devices for Epilepsy

- $\quad$ CACN - Tibbles Lecture: Thomas Opladen, Neurotransmitter Disorders- Classification, Clinical Presentation and Treatment Options

- $\quad$ CNSS - Penfield Lecture: Wouter Schievink, Spontaneous Intracranial Hypotension: Lessons Learned from the First 1000 Patients

- Society Prize Winners: present during Grand Plenary

12:15 pm to 1:45 pm - Lunch 'n Learn sessions

- $\quad$ The Spectrum of MS from Pediatric Data to SPMS

- $\quad$ Sudden Unexpected Death in Epilepsy (SUDEP)

2:00 pm to 4:30 pm - Multi-disciplinary Courses

- $\quad$ Neuromuscular

- $\quad$ Current Status of Neuro Palliative Care in Canada: Supportive Care for Patients and Families with Neurological Illness

- Movement Disorders

- $\quad$ Early Career Development

- Intracranial Hypotension: A Course for Neurologists and Neurosurgeons

4:30 pm to 7:00 pm - Exhibitors' Reception

Tuesday, June $26^{\text {th }}, 2018$

8:00 am to 4:15 pm - Society Days (Morning sessions 8 am to 10:30 am - Afternoon sessions 1:45 pm to 4:15 pm)

- $\quad$ Child Neurology (CACN) Day

am - Encephalopathy pm - Encephalopathy

- $\quad$ Neurophysiology (CSCN) Day

am - Beyond Routine EEG

$\mathrm{pm}-\mathrm{EMG}$

- $\quad$ Neurology (CNS) Day

am - Neuro-immunology: Neuro-immunological Diseases

pm - Neuro-immunology: Neurodiagnostics and Neurotherapeutics

- $\quad$ Neurosurgery (CNSS) Day

am - Controversies in Spinal Surgery-Cervical

am - Cranial-Skull Base Neurosurgery

$\mathrm{pm}$ - Controversies in Spinal Surgery-Lumbar

pm - Cerebrovascular Disorders - Endovascular and Open Approaches

10:45 am - 11:45 am - Poster Moderated Session

12:00 am to 1:30 pm - Lunch 'n Learn session

- Innovation in OR Technologies

$12: 00$ am to $1: 30 \mathrm{pm}$ - Lunch in the Exhibit Hall

7:00 pm - CNSF Social Event - Maritime Lobster Dinner \& Kitchen Party

Wednesday, June $27^{\text {th }}, 2018$

8:00 am to 9:00 am Chair's Select Abstracts

- $\quad$ CNS, CACN/ CSCN, CNSS/CSNR, - selected as part of abstract review process

9:15 - 11:15 am

- Hot Topics in Neurology: Top Papers

- Hot Topics in Neurosurgery

- Hot Topics in Child Neurology: Top 5 Papers

- Hot Topics in Clinical Neurophysiology: Advances in Epilepsy

11:15 am - 12:30 pm

- $\quad$ Lunch in Exhibit Hall

- $\quad$ Shaping Our Congress and Our Federation: Your hand in planning the Future of Continuing Medical Education in Canadian Neurosciences

$11: 45$ am to $12: 15 \mathrm{pm}$

- $\quad$ Dance in Parkinson's - Research to Practice

$12: 30 \mathrm{pm}$ to $2: 30 \mathrm{pm}$ - Grand Rounds 